\title{
SAF score and mortality in NAFLD after up to 41 years of follow-up
}

Hannes Hagström, Patrik Nasr, Mattias Ekstedt, Stergios Kechagias, Per Stal, Pierre Bedossa and Rolf Hultcrantz

\section{Journal Article}

\section{Tweet}

N.B.: When citing this work, cite the original article.

This is an electronic version of an article published in:

Hannes Hagström, Patrik Nasr, Mattias Ekstedt, Stergios Kechagias, Per Stal, Pierre Bedossa and Rolf Hultcrantz, SAF score and mortality in NAFLD after up to 41 years of follow-up, Scandinavian Journal of Gastroenterology, 2017. 52(1), pp.87-91.

Scandinavian Journal of Gastroenterology is available online at informaworldTM: http://dx.doi.org/10.1080/00365521.2016.1230779

Copyright: Taylor \& Francis: STM, Behavioural Science and Public Health Titles http://www.tandf.co.uk/journals/default.asp

Postprint available at: Linköping University Electronic Press

http://urn.kb.se/resolve?urn=urn:nbn:se:liu:diva-134617

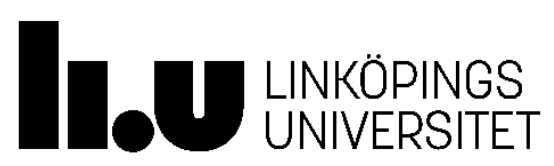




\section{SAF score and mortality in NAFLD after up to 41 years of follow-up}

Hannes Hagström ${ }^{1}$, Patrik Nasr ${ }^{2}$, Mattias Ekstedt ${ }^{2}$, Stergios Kechagias ${ }^{2}$, Per Stål ${ }^{1}$, Pierre Bedossa ${ }^{3}$, Rolf Hultcrantz ${ }^{1}$

${ }^{1}$ Center for Digestive Diseases, Division of Hepatology, Karolinska University Hospital, Stockholm, Sweden and Department of Medicine, Huddinge, Karolinska Institutet, Stockholm, Sweden

${ }^{2}$ Department of Medical and Health Sciences, Faculty of Medicine and Health Sciences, Linköping University, Linköping, Sweden

${ }^{3}$ Hôpital Beaujon, Department of Pathology, University Paris Diderot, Paris, France

Correspondence and reprint requests:

Hannes Hagström, Center for Digestive Diseases, Division of Hepatology, Karolinska University Hospital, 14186 Stockholm, Sweden

Phone: +46 (0) 858582305 Fax: +46 (0) 858582335

E-mail: hannes.hagstrom@ki.se

Running head: SAF score and mortality

Abbreviations: NAFLD, non-alcoholic fatty liver disease. NASH, non-alcoholic steatohepatitis. SAF, Steatosis Activity and Fibrosis. NAS, NAFLD activity score. FLIP, fatty liver inhibition of progress. HR, hazard ratio. CI, confidence interval.

Total word count (introduction to references): 2819. Abstract: 248. Tables: 4.

Figures: 1. Character count for title: 66 


\section{Author statement:}

Guarantor of article: Hannes Hagström

All authors approved the final version of the article, including the authorship list.

\section{Author contributions:}

Study conception and design: HH, PN, ME, SK, PS, PB, RH

Acquisition of data: $\mathrm{HH}, \mathrm{PN}, \mathrm{RH}$

Statistical analysis: $\mathrm{HH}$

Analysis and interpretation of data: $\mathrm{HH}, \mathrm{PN}, \mathrm{ME}, \mathrm{SK}, \mathrm{PS}, \mathrm{PB}, \mathrm{RH}$

Drafting of manuscript: $\mathrm{HH}$

Critical revision: $\mathrm{HH}, \mathrm{PN}, \mathrm{ME}, \mathrm{SK}, \mathrm{PS}, \mathrm{PB}, \mathrm{RH}$

Disclosure / Conflict of interest declaration: None

Writing Assistance: None.

\section{Grant Support (Funding):}

HH was supported by grants from the Stockholm County Council (ALF projects 20140329 and 20150403) and from the Royal Swedish Academy of Sciences Foundations (project ME2015-0011).

PS was supported by grants from the Swedish Society of Medicine (Gastroenterology Fund), Ruth and Richard Julins Fund and the Stockholm City Council (ALF project 2015403).

RH was supported by grants from the Swedish Cancer Foundation and King Gustaf V:s and Queen Victorias Freemason's Foundation. 


\section{Abstract}

Background and aims: A new score for the histological severity of non-alcoholic fatty liver disease (NAFLD), called SAF (Steatosis, Activity and Fibrosis) has been developed. We aimed to evaluate the impact of this score on overall mortality. Methods: We used data from 139 patients with biopsy-proven NAFLD. All biopsies were graded according to the SAF scoring system and disease severity was classified as mild, moderate or severe. Causes of death were extracted from a national, population based register. A Cox regression model, adjusted for sex, body mass index (BMI) and diabetes mellitus type 2, was applied.

Results: At baseline 35 patients presented with mild or moderate disease respectively, and 69 patients with severe disease. During follow-up (median 25.3 years, range 1.740.8) 74 patients died, 11 in the mild group (31\%), 18 in the moderate group (51\%) and 45 in the severe group (65\%), $\mathrm{p}=0.002$. Compared to patients with mild disease, patients with moderate disease did not have a significant increase in overall mortality (HR 1.83, 95\%CI 0.89-3.77, $\mathrm{p}=0.10$ ). Patients with severe disease had a significant increase in mortality (HR 2.65, 95\%CI 1.19-5.93, p=0.017). However, when adjusting for fibrosis stage, significance was lost (HR 1.85, 95\% CI 0.76-4.54, p=0.18). NASH, defined as per the FLIP algorithm, was not associated with mortality compared to not having NASH (HR 1.46, 95\%CI 0.74-2.90, p=0.28).

Conclusions: After adjustment for fibrosis, the SAF score was not associated with increased mortality in NAFLD. This finding should be corroborated in larger cohorts with similar follow-up time.

Keywords: NAFLD, NASH, SAF-score, NAS-score, fibrosis, mortality. 


\section{Introduction}

Non-alcoholic fatty liver disease (NAFLD) is the world's most prevalent liver disease, estimated to affect around 25 per cent of the global population (1, 2). A minority of patients develops non-alcoholic steatohepatitis (NASH), which indicates a more dismal prognosis $(3,4)$. A number of classification systems for the histological severity of NAFLD and NASH have been suggested $(5,6)$. The most used system is the NAFLD activity score (NAS), a semi-quantitative score based on the findings of steatosis, lobular inflammation and hepatocellular ballooning (6). However, this system was never intended as a NASH diagnosis tool, but primarily as an endpoint in clinical trials of NASH (7). Our research group among others has previously shown that the prognostic value of NAS for mortality is low, and that the most robust histological marker for future mortality is the fibrosis stage (8-10), which is not included in NAS.

A new scoring system for the histological severity of NAFLD has been suggested (11). The SAF score stands for $\underline{\text { Steatosis, }}$ Activity and Fibrosis. Uniquely for the SAF score, both the activity of the disease (based on evaluation of hepatocyte ballooning and lobular inflammation) as well as the presumed resulting damage (fibrosis) is included. Diagnosis of NASH is based on the fatty liver inhibition of progression (FLIP) algorithm (12), defined as the presence of both steatosis, lobular inflammation and ballooning according to the SAF score. The SAF score is currently used as a secondary endpoint in many currently ongoing clinical trials.

The aim of this study was to examine if disease severity according to the SAF score is associated with mortality in NAFLD. 


\section{Material and methods}

We performed a cohort study of 139 well-characterized Swedish patients with NAFLD who had undergone liver biopsy, with available histological slides. These patients were originally evaluated at the Linköping University Hospital, or the Karolinska University Hospital for the evaluation of elevated liver enzymes between 1974 and 1993 (13).

\section{Baseline characteristics at time of biopsy}

An additional chart review was performed in all cases. Patients with concurrent liver diseases at baseline were excluded at the time of liver biopsy using standard procedures and tests. All patients underwent a thorough interview with an experienced hepatologist at baseline to rule out use of alcohol >140 grams per week. Diabetes mellitus type 2 was defined as a diagnosis of diabetes mellitus type 2 or a fasting glucose $>126 \mathrm{mg} / \mathrm{dL}$. Height, measured in meters, and weight, measured in kilograms were used to calculate body mass index (BMI) as $\mathrm{kg} / \mathrm{m}^{2}$. The identification of the study cohort and baseline sampling of data including exclusion of hepatitis $\mathrm{C}$ virus infection has been discussed in detail elsewhere $(8,14,15)$. From that study, ten biopsies could not be retrieved and were excluded. In four cases, after chart review older biopsies than the ones included in the previous study were found and used to extend the study follow-up period. A flowchart for patient inclusion is presented in figure 1.

\section{Liver biopsy assessment}

Liver biopsies were originally performed using a $1.4 \mathrm{~mm}$ or $1.6 \mathrm{~mm}$ needle, with a Menghini technique. After on-site coordination of SAF scoring methodology with one of the SAF score inventors (P.B.), all biopsies were evaluated by a single hepatopathologist (R.H.), blinded to baseline characteristics and outcomes. Scoring 
was performed according to the SAF system with a score of $0-3$ for steatosis, $0-2$ for lobular inflammation, 0-2 for ballooning and 0-4 for fibrosis stage. There is no direct difference in fibrosis staging between the SAF and the NASH CRN systems. Activity score was defined as the lobular inflammation score plus the ballooning score, yielding a score of 0-4. All biopsies were of a good quality, as per the pathologist judgment. 17 of the biopsies had a size of less than 7 portal tracts, but were estimated to be well enough for evaluation. We also calculated the NAS in all biopsies, using a score of 0-3 for steatosis, 0-3 for lobular inflammation and 0-2 for ballooning, yielding a score of 0-8 as defined by Kleiner et al (6).

Disease severity

The histological severity of NAFLD according to the SAF score was classified as mild, moderate or severe. Mild disease was defined as a SAF fibrosis and activity score of no more than one in either score. Moderate disease was defined as either a SAF fibrosis and/or activity score equal to two. Severe disease was defined as a SAF fibrosis and/or activity score of at least 3. For example, a patient with an activity score of three, and a fibrosis score of zero would be classified as having severe disease. A model of the disease severity index is presented in table 1.

Presence of NASH was dichotomized as present or absent and defined according to the FLIP algorithm (12) as the presence of steatosis and both lobular inflammation and ballooning, of any grade.

\section{Outcome}

All Swedish citizens are assigned a unique personal identification number after birth or immigration, allowing for long-term follow-up and linkage of cohorts to national registries (16). We linked our cohort to the national, population-based Causes of Death Register (CDR) to register overall and disease-specific mortality. Patients were 
followed from the time of biopsy until death of any cause or until 2015-12-31 when the study period ended.

\section{Statistical analysis}

Differences in continuous parameters between patients with mild, moderate and severe disease activity were tested using the Kruskal-Wallis test and differences in categorical parameters using Fisher's exact test. A multivariate Cox regression model was used to examine the effect of disease severity on overall mortality. The model was first adjusted using an a priori defined approach for sex, BMI and presence of diabetes mellitus type 2 at baseline. Further adjustment was then performed for fibrosis stage as a continuous variable. In a separate sensitivity analyses, we excluded patients with fibrosis stage 3-4 $(\mathrm{N}=22)$ from the model.

We also tested the ability of other potential parameters to predict overall mortality in separate models. NASH, as defined by the FLIP algorithm (12), was tested against absence of NASH, and advanced fibrosis (stage 3-4) was tested against fibrosis stage 0-2. NAS and activity scores were tested as continuous parameters, adjusted for the same confounders.

\section{Ethical considerations}

The regional ethics committee at each study site approved the study. 


\section{Results}

At baseline, 35 patients had mild disease, 35 had moderate disease and 69 had severe disease, respectively. Baseline characteristics of the entire cohort are presented in table 2. Patients were followed for a median of 25.3 years (interquartile range [IQR] 17.8-31.2, range 1.7-40.8). Three patients emigrated during the study period and were lost to follow-up.

\section{Mortality during follow-up}

There were 74 deaths in the cohort during follow-up. In patients with mild disease 11/35 (31.4\%) died, in patients with moderate disease 18/35 died (51.4\%) and in patients with severe disease 45/69 (65.2\%) died ( $p=0.002)$. Median time of occurrence of death was 18 years after the initial liver biopsy (IQR 10-23). The main causes of death were cardiovascular disease $(\mathrm{N}=29)$, extrahepatic malignancies $(\mathrm{N}=17)$ and liver-related mortality $(\mathrm{N}=10)$. Stratified on disease severity, there were no cases of liver-related mortality in patients with mild disease, four cases in patients with moderate disease and six cases in patients with severe disease $(\mathrm{p}=0.27)$. Additionally, 18 patients died from other causes. Disease-specific mortality is presented in table 3.

\section{Regression analysis}

In the univariate analysis, patients with moderate disease according to the SAF score did not have a significant increase in overall mortality compared to patients with mild disease (Hazard ratio [HR] 1.83, 95\% confidence interval [CI] 0.89-3.77, p=0.10). Patients with severe disease according to the SAF score had a significant increase in overall mortality compared to patients with mild disease (HR 3.43, 95\%CI 1.80-6.55, $\mathrm{p}<0.001$ ). After adjustment for sex, BMI and diabetes mellitus type 2 at baseline, the increase in risk remained (HR 2.65, 95\% CI 1.19-5.93, p=0.017). 
After adjusting for fibrosis stage, significance for severe disease in the model was lost (HR 1.85, 95\%CI 0.76-4.54, p=0.19). Also, excluding patients with fibrosis stage 3-4 from the analysis resulted in loss of significance in the model (HR 1.92, 95\%CI 0.79-4.71, $\mathrm{p}=0.15)$.

NASH as defined per the FLIP algorithm was borderline associated with an increased risk of mortality in univariate (HR 1.66, 95\%CI 0.96-2.87, $\mathrm{p}=0.07$ ), but not in multivariate analysis (HR 1.46, 95\%CI 0.74-2.90, $\mathrm{p}=0.28$ ). Fibrosis stage 3-4 was associated with an increased risk of mortality both in the univariate (HR 3.33, 95\%CI 2.14-5.20, $\mathrm{p}<0.001$ ) and the multivariate (HR 3.13, 95\%CI 1.88-5.22, $\mathrm{p}<0.001$ ) model. NAS was associated with an increased risk for mortality in the univariate but not the multivariate analyses. However, activity score was associated with an increased risk of mortality after adjustment for sex, diabetes mellitus type 2 and BMI, but when adding fibrosis to the model, significance was lost. Hazard ratios for the univariate and multivariate analyses are presented in table 4. 


\section{Discussion}

This is the first study examining the association with mortality of the newly developed SAF score in patients with NAFLD. Our main finding is that even if a severe SAF score was indeed associated with increased mortality, this was highly dependent on the inclusion of fibrosis into the scoring system. Also, presence of NASH according to the FLIP algorithm could not predict mortality.

This is consistent with recent findings, both from our research group (8) and from others $(9,10)$, showing that fibrosis stage is the most significant histologic prognostic marker for mortality in NAFLD. However, the prognostic significance of the disease severity index according to the SAF score should be studied in larger cohorts, since this study may have been underpowered to detect smaller increases in risk. Vital for such studies, apart from larger sample sizes, is a long duration of follow-up as indicated by the fact that median time of death after liver biopsy in this study was 18 years. A small increase in risk would still be relevant, given the large NAFLD population in the general community $(1,2)$. Also, it might not be suitable to give the same impact in a scoring system to activity and fibrosis, as these are two different entities of the disease spectrum. One way to solve the issue if activity is associated with mortality independent of fibrosis could be to categorize NAFLD patients stratified on fibrosis stage with or without activity, and to study if patients with any given degree of fibrosis stage with activity have a worse prognosis than patients with the same fibrosis stage without activity. However, this sort of methodology would require a larger cohort, since it would mean ten different patient categories. Available histology, data on confounders and long-term follow-up would have to be present. 
Currently it could be argued that fibrosis stage is the most important factor for clinicians interpreting a liver biopsy result, when trying to obtain a prognosis in patients with NAFLD.

Strengths of this study are hitherto the longest ever duration of follow-up in NAFLD, the gold standard diagnosis of NAFLD using liver biopsy, and the very low loss to follow-up using high quality national population-based registers to ascertain disease-specific mortality. Limitations include a small sample size of 139 patients, which may have affected the power of the study and the risk of a type 2 error cannot be neglected. The small sample size disallowed us to use more potential confounders in the model, including age at biopsy. The study was performed at two tertiary clinics, which could indicate selection bias. However, all patients were originally evaluated for presence of persistently elevated liver enzymes, and not for suspicion of severe liver disease, such as decompensated liver disease. The fact that death occurred at a median of 18 years after the initial biopsy also supports the hypothesis that our patients were in general good health at that time.

The prevalence of NAFLD and NASH is increasing $(1,17)$ and NASH is estimated to increase the burden of liver disease and become the number one cause for need of liver transplantation in the near future $(18,19)$. There are several on-going clinical studies for NASH, ranging from early phase 1, to large, multi-national phase 3 studies $(20,21)$. Inclusion criteria for these studies include a NAS of four or greater, ignoring some patients with a phenotype that might have significant fibrosis, but low levels of NAS. Our results indicate that such patients (e.g. having a score of one for fat, one for lobular inflammation and one for ballooning equal to NAS 3) with higher stages of fibrosis have an increased risk of mortality. It could be argued that these patients should be included in treatment studies, as this group otherwise will not have 
access to treatment. The SAF score has been suggested to replace or be complementary to the NAS as an endpoint in clinical trials. The current study instead supports the use of a reduction of fibrosis stage as the most relevant endpoint, as this seems to be the most robust marker of mortality.

\section{Conclusion}

After adjustment for fibrosis, neither the SAF score nor NASH as defined per the FLIP algorithm was associated with increased mortality in NAFLD. This finding needs to be corroborated in larger cohorts with similar follow-up time. 


\section{References}

1. Loomba R, Sanyal A J. The global NAFLD epidemic. Nature reviews Gastroenterology \& hepatology 2013; 10(11): 686-90.

2. Younossi Z M, Koenig A B, Abdelatif D, Fazel Y, Henry L, Wymer M. Global Epidemiology of Non-Alcoholic Fatty Liver Disease-Meta-Analytic Assessment of Prevalence, Incidence and Outcomes. Hepatology 2015.

3. Vernon G, Baranova A, Younossi Z M. Systematic review: the epidemiology and natural history of non-alcoholic fatty liver disease and non-alcoholic steatohepatitis in adults. Alimentary pharmacology \& therapeutics 2011; 34(3): 274-85.

4. Singh S, Allen A M, Wang Z, Prokop L J, Murad M H, Loomba R. Fibrosis progression in nonalcoholic fatty liver vs nonalcoholic steatohepatitis: a systematic review and meta-analysis of paired-biopsy studies. Clinical gastroenterology and hepatology : the official clinical practice journal of the American Gastroenterological Association 2015; 13(4): 643-54.e1-9; quiz e3940 .

5. Brunt E M, Janney C G, Di Bisceglie A M, Neuschwander-Tetri B A, Bacon B R. Nonalcoholic steatohepatitis: a proposal for grading and staging the histological lesions. The American journal of gastroenterology 1999; 94(9): 2467-74.

6. Kleiner D E, Brunt E M, Van Natta M, et al. Design and validation of a histological scoring system for nonalcoholic fatty liver disease. Hepatology 2005; 41(6): 1313-21.

7. Brunt E M, Kleiner D E, Wilson L A, Belt P, Neuschwander-Tetri B A, Network N C R. Nonalcoholic fatty liver disease (NAFLD) activity score and the histopathologic diagnosis in NAFLD: distinct clinicopathologic meanings. Hepatology 2011; 53(3): 810-20.

8. Ekstedt M, Hagstrom H, Nasr P, et al. Fibrosis stage is the strongest predictor for disease-specific mortality in NAFLD after up to 33 years of follow-up. Hepatology 2015; 61(5): 1547-54.

9. Angulo P, Kleiner D E, Dam-Larsen S, et al. Liver Fibrosis, but No Other Histologic Features, Associates With Long-Term Outcomes of Patients With Nonalcoholic Fatty Liver Disease. Gastroenterology 2015.

10. Stepanova M, Rafiq N, Makhlouf $\mathrm{H}$, et al. Predictors of all-cause mortality and liver-related mortality in patients with non-alcoholic fatty liver disease (NAFLD). Digestive diseases and sciences 2013; 58(10): 3017-23.

11. Bedossa P, Poitou C, Veyrie N, et al. Histopathological algorithm and scoring system for evaluation of liver lesions in morbidly obese patients. Hepatology 2012; 56(5): 1751-9.

12. Bedossa P. Utility and appropriateness of the fatty liver inhibition of progression (FLIP) algorithm and steatosis, activity, and fibrosis (SAF) score in the evaluation of biopsies of nonalcoholic fatty liver disease. Hepatology 2014; 60(2): 565-75.

13. Hultcrantz R, Glaumann H, Lindberg G, Nilsson L H. Liver investigation in 149 asymptomatic patients with moderately elevated activities of serum aminotransferases. Scandinavian journal of gastroenterology 1986; 21(1): 10913.

14. Ekstedt M, Franzen L E, Mathiesen U L, et al. Long-term follow-up of patients with NAFLD and elevated liver enzymes. Hepatology 2006; 44(4): 865-73. 
15. Soderberg C, Stal P, Askling J, et al. Decreased survival of subjects with elevated liver function tests during a 28-year follow-up. Hepatology 2010; 51(2): 595-602.

16. Ludvigsson J F, Otterblad-Olausson P, Pettersson B U, Ekbom A. The Swedish personal identity number: possibilities and pitfalls in healthcare and medical research. European journal of epidemiology 2009; 24(11): 659-67.

17. Satapathy S K, Sanyal A J. Epidemiology and Natural History of Nonalcoholic Fatty Liver Disease. Seminars in liver disease 2015; 35(3): 221-35.

18. Wong R J, Aguilar M, Cheung R, et al. Nonalcoholic steatohepatitis is the second leading etiology of liver disease among adults awaiting liver

transplantation in the United States. Gastroenterology 2015; 148(3): 547-55.

19. Charlton M R, Burns J M, Pedersen R A, Watt K D, Heimbach J K, Dierkhising R A. Frequency and outcomes of liver transplantation for nonalcoholic steatohepatitis in the United States. Gastroenterology 2011; 141(4): 1249-53. 20. Hardy T, Anstee Q M, Day C P. Nonalcoholic fatty liver disease: new treatments. Current opinion in gastroenterology 2015; 31(3): 175-83. 21. Gawrieh S, Chalasani N. Pharmacotherapy for Nonalcoholic Fatty Liver Disease. Seminars in liver disease 2015; 35(3): 338-48. 


\section{Tables}

\begin{tabular}{|c|c|c|c|c|c|}
\hline \multicolumn{1}{|c|}{ Fibrosis } & 0 & 1 & 2 & 3 & 4 \\
\hline 0 & Mild & Mild & Moderate & Severe & Severe \\
\hline 1 & Mild & Mild & Moderate & Severe & Severe \\
\hline 2 & Moderate & Moderate & Moderate & Severe & Severe \\
\hline 3 & Severe & Severe & Severe & Severe & Severe \\
\hline 4 & Severe & Severe & Severe & Severe & Severe \\
\hline
\end{tabular}

Table 1. Disease severity index. Activity is the sum of the score of lobular inflammation

plus the score of ballooning, each scored as 0-2. 


\begin{tabular}{|l|l|l|l|l|l|}
\hline Parameter & $\begin{array}{l}\text { Total } \\
\text { N=139 }\end{array}$ & $\begin{array}{l}\text { Mild } \\
\text { N=35 }\end{array}$ & $\begin{array}{l}\text { Moderate } \\
\text { N=35 }\end{array}$ & $\begin{array}{l}\text { Severe } \\
\text { N=69 }\end{array}$ & P-value \\
\hline Sex (\% male) & $86(62)$ & $30(86)$ & $17(49)$ & $39(56)$ & 0.002 \\
\hline Age at biopsy & $52(39-58)$ & $41(35-54)$ & $46(40-55)$ & $56(44-61)$ & $<0.001$ \\
\hline DM2-diagnosis (\%) & $23(19)$ & $1(3)$ & $6(17)$ & $16(23)$ & 0.012 \\
\hline BMI (kg/m $)$ & $\begin{array}{l}28.0(25.7- \\
30.9)\end{array}$ & $\begin{array}{l}26.1(25.0- \\
28.7)\end{array}$ & $\begin{array}{l}28.1(26.6- \\
30.5)\end{array}$ & $\begin{array}{l}29.0(26.6- \\
32.0)\end{array}$ & 0.0046 \\
\hline ALT, IU/L & $73(50-105)$ & $54(37-76)$ & $73(51-107)$ & $82(58-112)$ & 0.0034 \\
\hline $\begin{array}{l}\text { Death during follow- } \\
\text { up (\%) }\end{array}$ & $74(53)$ & $11(34)$ & $18(51)$ & $45(61)$ & 0.002 \\
\hline Steatosis 0-3 ${ }^{1}$ & $1.9( \pm 0.9)$ & $1.3( \pm 0.6)$ & $2.3( \pm 0.8)$ & $2.1( \pm 0.8)$ & $<0.001$ \\
\hline $\begin{array}{l}\text { Lobular } \\
\text { inflammation 0-2 }{ }^{1}\end{array}$ & $1.3( \pm 0.6)$ & $0.7( \pm 0.4)$ & $1.2( \pm 0.4)$ & $1.7( \pm 0.4)$ & $<0.001$ \\
\hline Ballooning 0-2 ${ }^{1}$ & $0.9( \pm 0.7)$ & $0.03( \pm 0.2)$ & $0.8( \pm 0.4)$ & $1.4( \pm 0.6)$ & $<0.001$ \\
\hline Fibrosis 0-4 & $1.23( \pm 1.1)$ & $0.3( \pm 0.5)$ & $1.0( \pm 0.8)$ & $1.8( \pm 1.1)$ & $<0.001$ \\
\hline
\end{tabular}

Table 2. Characteristics of the cohort during baseline and follow-up. Data are presented as medians with interquartiles ranges (IQR) for continuous data, as absolute numbers and percentages for dichotomized data and as mean and standard deviations for ordinal data. Pvalue assessed using the Kruskal-Wallis test. ${ }^{1}$ As defined per the SAF score. Abbreviations: DM2, diabetes mellitus type 2. BMI, body mass index. ALT, alanine transaminase. IU, international units. L, litre. 


\begin{tabular}{|l|l|l|l|l|l|}
\hline $\begin{array}{l}\text { Cause of } \\
\text { death }\end{array}$ & Total & $\begin{array}{l}\text { Mild } \\
\text { disease }\end{array}$ & $\begin{array}{l}\text { Moderate } \\
\text { disease }\end{array}$ & $\begin{array}{l}\text { Severe } \\
\text { disease }\end{array}$ & P-value $^{\mathbf{1}}$ \\
\hline Cardiovascular & 29 & 5 & 7 & 17 & 0.94 \\
\hline $\begin{array}{l}\text { Extrahepatic } \\
\text { malignancy }\end{array}$ & 17 & 4 & 4 & 9 & 1.0 \\
\hline Liver-related & 10 & 0 & 4 & 6 & 0.27 \\
\hline Other & 18 & 2 & 3 & 13 & 0.16 \\
\hline
\end{tabular}

Table 3. Causes of death in the entire cohort and stratified on disease severity.

${ }^{1}$ Analysed using Fisher's exact test. 


\begin{tabular}{|c|c|c|c|c|c|c|}
\hline Parameter & $\begin{array}{l}\text { Univariate } \\
\text { model }\end{array}$ & $\begin{array}{l}\text { P- } \\
\text { value }\end{array}$ & $\begin{array}{l}\text { Multivariate } \\
\text { model }^{1}\end{array}$ & $\begin{array}{l}\text { P- } \\
\text { value }\end{array}$ & $\begin{array}{l}\text { Multivariate } \\
\text { model }^{2}\end{array}$ & $\begin{array}{l}\text { P- } \\
\text { value }\end{array}$ \\
\hline $\begin{array}{l}\text { Moderate } \\
\text { SAF score } \\
\text { (compared to } \\
\text { mild) }\end{array}$ & $\begin{array}{l}1.82 \\
0.89-3.77\end{array}$ & 0.10 & $\begin{array}{l}1.23 \\
0.50-3.04\end{array}$ & 0.64 & $\begin{array}{l}1.07 \\
0.43-2.64\end{array}$ & 0.89 \\
\hline $\begin{array}{l}\text { Severe SAF } \\
\text { score } \\
\text { (compared to } \\
\text { mild) }\end{array}$ & $\begin{array}{l}3.43 \\
1.80-6.55\end{array}$ & $<0.001$ & $\begin{array}{l}2.65 \\
1.19-5.93\end{array}$ & 0.017 & $\begin{array}{l}1.85 \\
0.76-4.54\end{array}$ & 0.18 \\
\hline $\begin{array}{l}\text { NASH } \\
\text { according to } \\
\text { FLIP } \\
\text { algorithm }\end{array}$ & $\begin{array}{l}1.66 \\
0.96-2.87\end{array}$ & 0.07 & $\begin{array}{l}1.17 \\
0.57-2.41\end{array}$ & 0.67 & $\begin{array}{l}0.86 \\
0.39-1.93\end{array}$ & 0.72 \\
\hline $\begin{array}{l}\text { Fibrosis } \\
\text { stage } \\
\text { (continuous) }\end{array}$ & $\begin{array}{l}1.53 \\
1.27-1.84\end{array}$ & $<0.001$ & $\begin{array}{l}1.45 \\
1.16-1.80\end{array}$ & 0.001 & - & - \\
\hline $\begin{array}{l}\text { Fibrosis } \\
\text { stage (3-4 vs } \\
0-2)\end{array}$ & $\begin{array}{l}3.33 \\
2.13-5.20\end{array}$ & $<0.001$ & $\begin{array}{l}3.13 \\
1.88-5.22\end{array}$ & $<0.001$ & - & - \\
\hline NAS (0-8) & $\begin{array}{l}1.17 \\
1.01-1.36\end{array}$ & 0.036 & $\begin{array}{l}1.02 \\
0.85-1.22\end{array}$ & 0.85 & $\begin{array}{l}0.90 \\
0.73-1.10\end{array}$ & 0.30 \\
\hline $\begin{array}{l}\text { Activity score } \\
(0-4)\end{array}$ & $\begin{array}{l}1.53 \\
1.20-1.93 \\
\end{array}$ & $<0.001$ & $\begin{array}{l}1.34 \\
1.02-1.76\end{array}$ & 0.036 & $\begin{array}{l}1.18 \\
0.85-1.64\end{array}$ & 0.32 \\
\hline
\end{tabular}

Table 4. Hazard ratios. Hazard ratios for the selected models, including 95\% confidence intervals. ${ }^{1}$ Adjusted for sex, BMI and diabetes mellitus type 2 at baseline. ${ }^{2}$ Further adjusted for fibrosis stage. Abbreviations: SAF, Steatosis Activity Fibrosis. Vs, versus. NASH, nonalcoholic steatohepatitis. FLIP, Fatty Liver Inhibition of Progress. BMI, body mass index.. NAS, NAFLD activity score. 


\section{Figure legend}

Fig. 1. Flowchart for participant inclusion.

229 patients originally evaluated during 1974-1993. 74 of these biopsies were missing for the previous published study (8). For this study, we were unable to retrieve another 10 biopsies. 139 subjects remained for SAF scoring and analysis. 


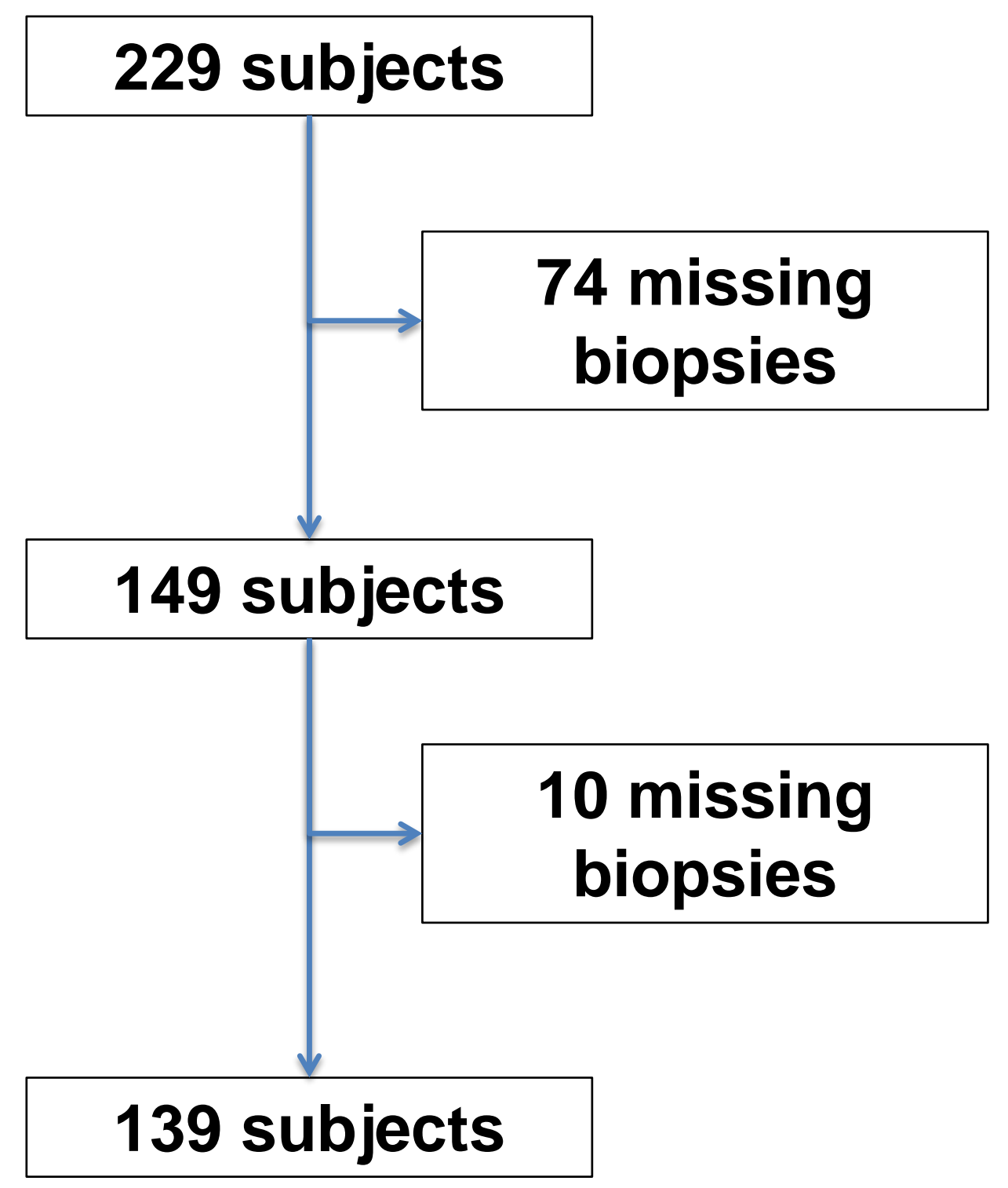

